\title{
FREE AND CUED SELECTIVE REMINDING DISTINGUISHES ALZHEIMER'S DISEASE FROM VASCULAR DEMENTIA
}

\author{
Ellen Grober, PhD, \\ Department of Neurology, Albert Einstein College of Medicine, and Montefiore Medical Center, \\ Bronx, NY \\ Charles Hall, PhD, \\ Department of Epidemiology and Population Health, Department of Neurology, Albert Einstein \\ College of Medicine, Bronx, NY
}

Amy E. Sanders, MD, and Department of Neurology, Albert Einstein College of Medicine and Montefiore, Medical Center, Bronx, NY

Richard B. Lipton, MD

Department of Neurology, Department of Epidemiology and Population Health, Albert Einstein College of Medicine, Bronx, NY

To the Editor: Although clinicians have long been interested in the possible role of cognitive profiles in distinguishing patients with Alzheimer's disease (AD) from those who have vascular dementia $(\mathrm{VaD})$, this distinction is not straightforward. Because impairment in executive functioning can limit learning in elderly people, ${ }^{1}$ decrements in performance on conventional memory testsmay result from primary memory deficits or apparent memory deficits due in part to executive and attentional deficits. Thus, the memory profiles of $\mathrm{AD}$ and $\mathrm{VaD}$ may appear similar when memory is assessed with tests that depend upon frontal and attentional processes. Distinguishing the profiles may require assessing memory with tests that control attention and cognitive processing. It was hypothesized that patientswith $\mathrm{VaD}$ would benefitmore from controlled learning procedures than patients with $\mathrm{AD}$, whose hallmark deficit is memory impairment.

The Free and Cued Selective Reminding Test (FCSRT) controls the learning conditions by having subjects search a card containing four pictures of items (e.g., grapes, toaster) that go with unique category cues (e.g., fruit, kitchen appliances). After all four items are identified, immediate cued recall of just those four items is tested. After controlled learning has been completed for all 16 items, there are three test trials consisting of free recall, followed by cued recall for those items not retrieved using free recall. The sum of free and cued recall on each trial is called total recall. The FCSRT procedure is described in detail elsewhere. ${ }^{2}$

These controlled learning procedures were designed to minimize inattention, promote deep semantic processing, and control conditions during encoding that are reinstated at retrieval for maximum recall.

The study took place in an urban academic primary care practice following procedures approved by the local institutional review board. Each study participant underwent a

\footnotetext{
Author Contributions: $\mathrm{CH}$ was responsible for data analysis and interpretation. AES was responsible for sub-typing patients. RBL was responsible for analysis and interpretation. EG oversaw all aspects of the study including concept and design, acquisition of subjects and data, and interpretation and preparation of the manuscript.
} 
neuropsychological evaluation consisting of a screening battery and an independent diagnostic battery used to determine cognitive status. ${ }^{3}$ Informants completed the structured Clinical Dementia Rating Scale (CDR) interview. ${ }^{4}$ Dementia diagnosis and CDR score were established according to consensus of a neuropsychologist (EG), a geriatrician, and a geriatric psychiatrist using Diagnostic and Statistical Manual of Mental Disorders, Fourth Edition (DSM-IV) criteria for dementia ${ }^{5}$ without knowledge of FCSR results. The study neurologist (AES) subsequently assigned dementia subtypes using established criteria for probable or possible $\mathrm{AD}^{6}$ and probable or possible $\mathrm{VaD} .^{7}$

Participants were 344 African-American and Caucasian patients aged 65 and older who scored 18 or higher on the Mini-Mental State Examination (MMSE). Of the 60 participants (17\%) who met DSM-IV criteria for dementia, most with very mild dementia (CDR 0.5), 27 (45\%) had possible or probable $\mathrm{AD}$, and 14 (23\%) had possible or probable VaD. The eight (13\%) participants who had mixed dementia $(\mathrm{AD}+\mathrm{VaD})$ were grouped with the patients with $\mathrm{AD}$. Twelve patients with other dementias were excluded from this analysis. Two hundred eightythree patients did not meet criteria for dementia.

Established cutscores were used to determine the sensitivity and specificity of free recall ${ }^{8}$ and total recall ${ }^{2}$ for patients with $\mathrm{AD}$ versus $\mathrm{VaD}$ (Table 1). Eighty-three percent of patients with $\mathrm{AD}$ and $79 \%$ of patients with $\mathrm{VaD}$ displayed impaired free recall. Specificity of free recall was $76 \%$ (216/283). Impaired free recall in patients without dementia was associated with CDR rating; $82 \%$ of patients with impaired free recall and $41 \%$ of patients with intact free recall had a CDR of 0.5. As predicted, sensitivity of total recall varied as a function of dementia subtype. Seventy-one percent (25/35) patients with AD had impaired total recall, whereas 79\% (11/14) patients with $\mathrm{VaD}$ patients had intact total recall. This differentiation was not due to differences in severity of dementia between patient groups as measured by the sum of CDR box scores. ${ }^{4}$ A logistic regression model was fit to the data with impairment on total recall as the outcome. Dementia subtype was a significant predictor; patients with AD were 9.17 times as likely to have impaired total recall as patients with $\mathrm{VaD}$; they were 7.74 as likely after controlling for dementia severity. Specificity of total recall was excellent; only $6 \%$ of patients without dementia had impaired total recall.

The results confirmed the predictions; impaired free recall was common in patients with $\mathrm{AD}$ and $\mathrm{VaD}$, but impaired total recall occurred only in patients with $\mathrm{AD}$, underscoring the centrality of memory deficits to this disorder. In contrast, patients with VaD displayed intact total recall, showing the expected benefit of controlled learning, perhaps because, in patients with $\mathrm{VaD}$, the frontal and attentional system plays a more profound and important role. These results demonstrate the promise of FCSR for distinguishing between AD and non-AD dementias, further enhancing its sensitivity and specificity as a case-finding tool for identifying preclinical and early dementia. $3,9,10$

\section{ACKNOWLEDGMENTS}

The FCSRT is copyrighted by the Albert Einstein College of Medicine (AECOM) and is available from the AECOM for free when used for research purposes.

Supported in part by National Institute on Aging Grants AG017854 and AG03949.

Conflict of Interest: The editor in chief has reviewed the conflict of interest checklist provided by the author and has determined that except for EG none of the authors have any financial or any other kind of personal conflicts with this manuscript.

EG receives a small royalty for commercial use of the FCSRT.

Sponsor's Role: None. 


\section{REFERENCES}

1. Light L. Memory and aging: Four hypotheses in search of data. Ann Rev Psychol 1991;42:333-376. [PubMed: 2018397]

2. Grober E, Buschke H. Genuine memory deficits in dementia. Dev Neuropsy-chol 1987;3:13-36.

3. Grober E, Hall C, McGinn M, et al. Neuropsychological strategies for detecting early dementia. J Int Neuropsychol Soc 2008;14:130-142. [PubMed: 18078539]

4. Morris JC. Clinical dementia rating: Current version and scoring rules. Neurology 1993;43:2412-2414. [PubMed: 8232972]

5. American Psychiatric Association. Diagnostic and Statistical Manual of Mental Disorders. Vol. 4th Ed.. Washington, DC: American Psychiatric Association Press; 1994.

6. McKhann G, Drachman D, Folstein M, et al. Clinical diagnosis of Alzheimer's disease: Report of the NINCDS-ADRA work group under the auspices of department of health and human services task force on Alzheimer's disease. Neurology 1984;34:939-944. [PubMed: 6610841]

7. Chui HC, Victoroff JI, Margolin D, et al. Criteria for the diagnosis of ischemic vascular dementia proposed by the State of California Alzheimer's Disease Diagnostic and Treatment Centers. Neurology 1992;42:473-480. [PubMed: 1549205]

8. Grober E, Lipton RB, Hall C, et al. Memory Impairment on free and cued selective reminding predicts dementia. Neurology 2000;54:827-832. [PubMed: 10690971]

9. Grober E, Hall C, Lipton RB, et al. Primary care screen for early dementia. J Am Geriatr Soc 2008;2:206-213. [PubMed: 18179486]

10. Sarazin M, Berr C, De Rotrou J, et al. Amnestic syndrome of the medial temporal type identifies prodromal AD: A longitudinal study. Neurology 2007;69:1859-1867. [PubMed: 17984454] 
Table 1

Sensitivity and Specificity of Free Recall and Total Recall for Patients with Alzheimer's Disease (AD) and Vascular Dementia $(\mathrm{VaD})$

\begin{tabular}{|c|c|c|c|}
\hline Recall & No Dementia & $\mathbf{A D}$ & VaD \\
\hline \multicolumn{4}{|c|}{ Free recall score } \\
\hline$>24, \mathrm{n}$ & 216 & 6 & 3 \\
\hline$\leq 24, \mathrm{n}$ & 67 & 29 & 11 \\
\hline Specificity & 0.76 & & \\
\hline Sensitivity & & 0.83 & 0.79 \\
\hline \multicolumn{4}{|c|}{ Total recall score } \\
\hline$>44, \mathrm{n}$ & 267 & 10 & 11 \\
\hline$\leq 44, \mathrm{n}$ & 16 & 25 & 3 \\
\hline Specificity & 0.94 & & \\
\hline Sensitivity & & 0.71 & 0.21 \\
\hline
\end{tabular}

